\title{
Nudge and Improvement of Quality in Public Service: Process and Enlightenment
}

\author{
Hongbin Lin \\ School of Humanities and Law, Northeastern University, Shenyang 110000, China \\ Email: 4654711078@qq.com
}

\begin{abstract}
The improvement of quality in public service is an inevitable requirement during the development of public service practices. Public satisfaction is an important criterion to measure the quality of public service. The value rationality of public behavior is a significant factor that affects public satisfaction and governments' credibility. In recent years, "nudge" theory in behavioral economics has received wide attention and application.
\end{abstract}

Keywords: nudge, quality of public service, behavior

\section{Introduction}

The development of governance theory resulted in part from a game of hypothesis that any problems caused by government can be solved by more governmental methods. At present, the frontier study of public service is how to improve the quality of public service, to meet public demand and improve public satisfaction. From the perspective of satisfying public needs and improving public satisfaction, scholars believe that public service quality is the sum of satisfying public needs and improving public satisfaction in the process of providing public services by the public sectors or the third sectors. During the study, scholars found that public behavior and choice in public services are of great significance to meet public needs. ${ }^{[1]}$

With the rise of behavioral economics, scholars have found that in the process of improving the quality of public services, the behavior of public service objects is one of the important influencing factors except the system, technology and organization. The quality of public services and the behavior of participants interact with each other. A behavioral economist named Richard Thaler and a jurist named Cass Sunstein published the book "Nudge: How to Make the Best Decisions about Health, Wealth, and Happiness" which proposed the "Nudge" theory formally in 2008. Cass Sunstein puts forward the viewpoint of "behavioral market failure" and summarizes the advantages and disadvantages of government "paternalism", and expounds the relationship between them. "Behavioral market failure" is the widely held view among behavioral economists that people often make decisions that are not in their best interests. ${ }^{[2]}$ Governmental "paternalism" refers to the official remedy for decisions that do not harm to others but are possibly to have serious consequences to correct people's mistakes in choosing to achieve their goals. In practice, the most reasonable form of such official remedy is the "nudge". Taylor and Sunstein also argue that governments can use more subtle methods to guide the public choice. The world bank report in 2015 has found that the effectiveness of public policy objectives is closely related to the depth of understanding of participants' behaviors.

\section{Definition of "nudge" theory}

The rise of "nudge" theory stems from the development of behavioral economics. Compared with traditional economics, behavioral economics was born during the second world war accidentally, which is still in its initial phase of academic evolution and mainly deals with the scarcity, uncertainty and complexity of traditional economics.

Behavioral economists believe that behavioral economics embodies the "nature" of people sufficiently. Therefore, when they interpret an issue and make a decision, they take into account the internal and external causes of the impact, including values, the sense of responsibility of the subject, social identity and social influence. Through rational allocation of internal and external factors, "Nudging" influences and promotes the public to make reasonable choices. ${ }^{[3]}$

In theory, "nudge" does not against long-term interest of the public. As a result, the public has made "more rational" decisions about the preferences of architects, which are consistent with the "limited rationality" theory of behavioral economics. According to existing research, "nudge" has three characteristics. One is that "nudge" is different from command. The public has the freedom to choose. Second, the risk of "nudge" on the impact of decision-making is minimized or even avoided. Third, implementation of the objects can benefit from nudge. 


\section{The application of the nudge theory}

With the deepening of the research on public service quality, the satisfaction of public service objects and the quantity, quality, efficiency, fairness, output and value for money of public service input have become the seven standards to measure the quality of public service, and the importance of public value concept and technology route is becoming equal increasingly. The development of the nudge theory and the practice of public administration is based on the emphasis of human value and demand in the field of public administration.

Dan Ariely, a behavioral economist, describes more than a dozen factors that influence behavioral subjects to make irrational decisions in his book systematically_Predictably Irrational. Due to the "predictability" of irrational behaviors caused by these influencing factors, the application scope of "nudge" began to expand and developed in the field of public administration.

In fact, the "nudge" theory was applied to public administration earlier than it received widespread attention. In the 1990s, some sociologists attributed the McDonaldization of public organizations to the result of the process of social rationalization. Some scholars regard the McDonaldization of public organization as the beginning of "nudge" applied to public administration. As put forward the theory of "nudge" in 2008 formally, the former British prime minister David Cameron took the lead in the formation of the cabinet which is a special group made up by 13 people in $2010 .{ }^{[4]}$ Nudge Unit and application of the psychology research and behavioral economics in public policy and public service had begun officially. In 2010, a report showed some of the results of the "nudge" optimization by this group. For example, a pilot program at job centers increased employment rates effectively by streamlining job search procedures and requiring job seekers to make "proactive commitments" to curb inertia at work in four cities.

After that, the U.S. government established "the White House Social and Behavioral Science Team" (SBST) designed to take research on human behavior and design a more efficient policy in order to make the federal government provide better public services for individuals, families, enterprises, community and save money for taxpayers in the meanwhile in 2014. For example, participation in the military's thrifty savings plan (TSP) doubled, and college enrollment among low-income students rose 8.3 percent. In Europe, the Dutch government introduced "nudge" in the field of public administration. Despite the considerable ethical controversy, government officials were still active and held a seminar on "nudge" policies in 2014.At the Dutch ministry of infrastructure and environment, new behavioral insights have been applied to a number of its initiatives.

\section{Contend of nudge}

Scholars hold different opinions in the process of "nudge" from theory to application. In general, relative to the practice effect of "nudge" theory, related disputes are mostly reflected in the theoretical level academically. Some scholars doubted or even opposed that whether "nudge" can become the fifth governmental governance mode besides Hierarchy, Markets, Networks and Persuasion. Generally, the objections focus on the three aspects as follows. The first one is the question about $t$ effectiveness of "nudge" as a kind of lasting behavioral change means by some scholars. Cotterill questioned the validity of the "nudge" intervention random control group and pointed out that there is evidence to prove many successful "nudges" are not "nudges" actually. He also stressed that the "nudge" in dealing with the collective behavior rather than the individual behavior in some cases. Secondly, in the view of free economics, the "nudge" is equivalent to " Manipulation" in a sense, which can cause ethical controversy in the era of contemporary liberalism and affect the public free choice. Some scholars said that the more influence of the choice from the designer, the greater the abuse of its influence. Goodwin argues that the use of "nudge" in British policymaking should be rejected because it violates the coalition government's desire to promote ideas such as power, freedom and fairness. The third one is to question those who "promotes" the implementation. Lore Krebs, President of the British science society, said nudge was not a "panacea". Michael Thomas, an economist at Utah state university, says he is skeptical of any group that promotes "nudge", arguing that its members do not know all the options better than policymakers necessarily and are more likely to push the wrong ones. ${ }^{[5]}$

\section{The enlightenment of "nudge" to improve the quality of public service}

From the perspective of the ways and characteristics of "nudge", no matter how the public service implementor "nudge", it should be based on certain principles.

\subsection{Principle of simplify}

The U.S. government had embarked on a "simplification" campaign. The aim is to innovate the governance model. In 
public service activities, the public prefers to deal with all possibilities using the obvious options rather than prioritizing the search for better solutions. In general, simplification takes three forms: adjustment, addition, and reorganization. It is important not to oversimplify. For example, the White House social and behavioral science task force began implementing student aid programs in 2015 to help increase college enrollment and make loans affordable to families. ${ }^{[6]}$

\subsection{Principle of effectiveness}

In public services, administrative cost expenditure and public service efficiency are interdependent. Efficient public service is a positive feedback to administrative cost expenditure, while inefficient public service can restrain the expenditure of administrative cost. From the perspective of social psychology, "nudge" can affect the preference of government personnel for public expenditure. ${ }^{[7]}$ The White House social and behavioral science group and the department of agriculture's economic research service have introduced programs that promote double-sided printing, resulting in significant savings in administrative costs.

\subsection{Principles of perception}

"Nudge" is an effective response to perceived inertia. Taylor and Sunstein's research on the default factory settings of mobile phones came to two conclusions: the role of laziness cannot be ignored; Inertia can be controlled. A study in the 1980s found that most members of the public chose a random allocation of assets when they participated in U.S. 401 (K) plans, and most of them stayed the same throughout their lifetimes. Thus, the default option to allocate pension assets can provide a powerful boost. When government departments design pension plans, they can design default options for different groups of people that are in the public's long-term interest.

\subsection{Principle of situation}

Due to the existence of "relative rationality" of people and social influence, the public is easily influenced by social situations and the words and deeds of others when choosing public services. There are two ways of "nudge" to guide conformity psychology and habitual behavior: using the continuous "nudge" of conformity psychology and improving the public's blind obedience psychology. San Calamento, California has introduced a new bill to reduce the energy consumption of homes. The move has had a noticeable impact on public electricity usage ${ }^{[8]}$ When you find that you use far more electricity than your neighbors, you actively reduce your energy consumption.

\section{Conclusion}

Public satisfaction is a micro scale to measure the quality of public services. The positive traction of public interests to individual interests is conducive to the improvement of public service quality. In the future research, the in-depth exploration of "nudge" and the scientific consideration of public service quality based on this will help promote the development of government governance theory and practice. It should be pointed out that since behavioral economics is still a young discipline, the cross-study of behavioral economics and public administration in domestic academic circles is still in its infancy.

\section{References}

[1] Chen Wenbo. Evaluation and improvement of public service quality: research review. Chinese Administration. 2012; (3): 39-43.

[2] Li Deguo, Cai Jingjing. Public service quality improvement based on nudge theory - a research framework. Journal of Jiangsu University of Administration. 2016; (5): 109-116.

[3] Richard Taylor, Cass Sunstein. Nudge: how to make the best decisions about health, wealth and happiness. Beijing: Citic Press. 2015.

[4] Chen Zhenming, geng xu. Theory and practice progress of public service quality improvement in China. Journal of Xiamen University. 2016; (1): 58-66.

[5] Social and Behavioral Sciences Team Annual Report (2015-2016), Executive Office of the President National Science and Technology Council.

[6] Li Xiaoqian, Lu Xiaoli, xu hao, liu qiushi. Progress and enlightenment of foreign experimental research on public management. Public Management Review. 2017; (2): 16-34.

[7] Frank Mols, S.Alexander Haslam, Jolanda Jetten, Niklas K. Steffens. Why a Nudge Is Not Enough: A Social Identity Critique of Governance by Stealth. European Journal of Political Research. 2015; (54): 81-98. 
[8] Mark Whitehead, Rhys Jones, Jessica Pykett. Nudge:The Real Ethical Debate? Rethinking the Ethics of Nudging. The Psychological State. 2014; (10): 469-479. 